\title{
Sustainable African Built Environments
}

\author{
Jeremy Gibberd* \\ University of Pretoria and CSIR, Pretoria, South Africa
}

\begin{abstract}
Carbon emission scenarios are used as key inputs to the sustainability and built environment strategies and policies of many developed countries. Decisions and direction in these are based on carbon emission models which show the optimum mix of interventions required to achieve carbon emission reductions or stabilization. Developing countries and countries in Africa are now under increasing pressure to adopt carbon emission criteria as the key focus of their built environment policies and strategies. This paper argues against this. It suggests that focusing on carbon emissions is likely to result in limited resources and timeframes being exhausted trying to achieve reductions and valuable opportunities to build long term sustainable solutions will be lost. It also argues that increasingly scarce resources, infrastructure backlogs, the lifespan of infrastructure and buildings (50+ years) and the limited timeframes for addressing climate change mean that African countries cannot address carbon emission reductions first, and then address sustainability later; they need to address both at once. This paper also argues that while reducing carbon emissions may benefit companies involved in renewable energy and energy efficient technologies, it does not lead to sustainability. Sustainability is complex and requires the achievement of minimum quality of life standards as well as a balance between environmental and human systems. Carbon emission reduction technologies, by themselves, will not achieve this. This paper draws on a definition of sustainability developed by the World Wildlife Fund to show how a sustainable development approach can address carbon emissions while building more sustainable systems. It describes the Built Environment Sustainability Tool (BEST) developed by the author in 2011 and shows how this can be used to assess built environments and identify appropriate mixes of interventions to improve the sustainability performance of built environments. It also outlines interventions that can be used to support the development of more sustainable African built environments.
\end{abstract}

Keywords: Sustainability; Sustainable development; Built environments; Africa

\section{Introduction}

Carbon emission projections are widely used in developed countries to inform built environment development strategies and policy. Projections are used to identify the most appropriate interventions required to achieve carbon emission stabilization or downward trajectories in order to meet global or national targets. Increasingly, African countries are now being encouraged to use these projections and focus on carbon emission reductions as a key target of national built environment and development policies and strategies (Barker, 2007; Winkler, 2007; United Nations Environment Programme, 2010).

There are, however, problems with using carbon emissions as the key input into development strategies. Increasing carbon dioxide levels in the atmosphere are a symptom of imbalance in planetary systems and, as with the human body, a sole focus on addressing symptoms does not lead to a cure. A focus on addressing carbon emission symptoms often results in the selection of standard technological solutions such as renewable energy or solar water heaters.
These solutions are appealing as their impacts can be readily modelled and costed and simple uniform implementation processes can be used to apply these rapidly and widely across large urban areas and even within countries as a whole.

These solutions however do not take into account pressing local social and economic circumstances. This results in the selected solutions not being implemented as these are not seen as a local priority and therefore are seen as inappropriate. Alternatively, if these are implemented, the technological solutions (often imported) consume valuable resources that are then not available to address local social and economic issues.

This approach is reflected in green building rating tools which emphasize technological solutions such as sophisticated building management and metering systems, air-conditioning systems and low volatile organic compound (VOC) paints and carpets. This assumes that this technology is appropriate, available, affordable and should be aspired to. It also assumes that there is the technical capacity and ongoing funding to install, and maintain,

\footnotetext{
*Email: itshose@gmail.com. 
these types of installations. In many African built environments these assumptions are not correct and instead of aspiring to imported sophisticated technology it may be more worthwhile to focus on local responsive solutions.

Instead of focusing on partial technological solutions which address symptoms of environmental imbalance, can integrated human and environmental systems which work together to achieve sustainability be built? This paper argues that integrated human and environmental systems must be the goal strived for in African built environments. An essential first step in implementing this goal is a definition of sustainability that captures the key characteristics of human and environmental systems (Curwell \& Cooper, 1998).

\section{Defining Sustainability}

A suitable definition of sustainability has been developed by the World Wildlife Fund (WWF). This describes sustainability as being the achievement of above 0.8 on the Human Development Index (HDI) and the achievement of an Ecological Footprint (EF) below 1.8 global hectares per person (World Wildlife Fund, 2006).

The Human Development Index was developed by the United Nations as an alternative to economic progress indicators and aimed to provide a broader measure that defined human development as a process of enlarging people's choices and enhancing human capabilities (United Nations Development Programme, 2007). The measure is based on:

- A long healthy life, measured by life expectancy at birth

- Knowledge, measured by the adult literacy rate and combined primary, secondary and tertiary gross enrolment ratio

- A decent standard of living, as measured by the GDP per capital in purchasing power parity (PPP) in terms of US dollars

In order to measure the HDI, minimum and maximum values (goalposts) are chosen for each of the above indicators. These goalposts are outlined below:

\begin{tabular}{|c|c|c|}
\hline Dimensional indicator & $\begin{array}{l}\text { Maximum } \\
\text { value }\end{array}$ & $\begin{array}{l}\text { Minimum } \\
\text { value }\end{array}$ \\
\hline Life expectancy at birth & 85 & 25 \\
\hline Adult literacy rate $(\%)$ & 100 & 0 \\
\hline $\begin{array}{l}\text { Combined gross enrolment } \\
\text { ratio }(\%)\end{array}$ & 100 & 0 \\
\hline GDP per capita (PPP US\$) & 40,000 & 100 \\
\hline
\end{tabular}

The HDI is the average of three indexes:

$$
\begin{aligned}
\mathrm{HDI}= & 1 / 3(\text { life expectancy index }) \\
& +1 / 3(\text { education index })+1 / 3(\mathrm{GDP} \text { index })
\end{aligned}
$$

An Ecological Footprint is an estimate of the amount of biologically productive land and sea required to provide the resources a human population consumes and absorb the corresponding waste. These estimates are based on consumption of resources and production of waste and emissions in the following areas:

- Food, measured by type and amount of food consumed

- Shelter, measured by size, utilization and energy consumption

- Mobility, measured by type of transport used and distances travelled

- Goods, measured by type and quantity consumed

- Services, measured by type and quantity consumed

- Waste, measured by type and quantity produced

The area of biologically productive land and sea for each of these areas is calculated in global hectares (gha) and then added together to provide an overall ecological footprint (Wackernagel \& Yount, 2000). This measure is particularly useful as it enables the impact of infrastructure and lifestyles to be measured in relation to the Earth's carrying capacity of 1.8 gha per person.

\section{National development trajectories}

National figures using the HDI and the EF have been combined in Figure 1 (World Wildlife Fund, 2006). This shows that countries in Europe and North America have very high EFs and acceptable HDIs (above 0.8), while countries in Africa have unacceptably low HDIs (below 0.8) but have EFs within the biosphere's allowable capacity per person.

Figure 1 also indicates national development trajectories (the lines between the diamonds and dots). For example, the trajectory of the USA has been steep, with a large increase in their EF and relatively limited improvement in their HDI in the last 20 years. In contrast, Hungary, over the same time period, has improved their HDI to achieve the minimum sustainability criteria and, at same time, reduced their EF. This suggests that strategies based on an understanding of current HDI and EF performance can support a shift towards sustainability (Moran et al., 2008). This is supported by Holden and Linnerud (2007) who argue through reference to PPP and EF measures that developing and developed countries require different strategies to achieve sustainability.

There is therefore a strong argument that built environment development strategies should respond to local EF and HDI performance and, through the provision of appropriate characteristics, support development trajectories aimed at achieving sustainability. 


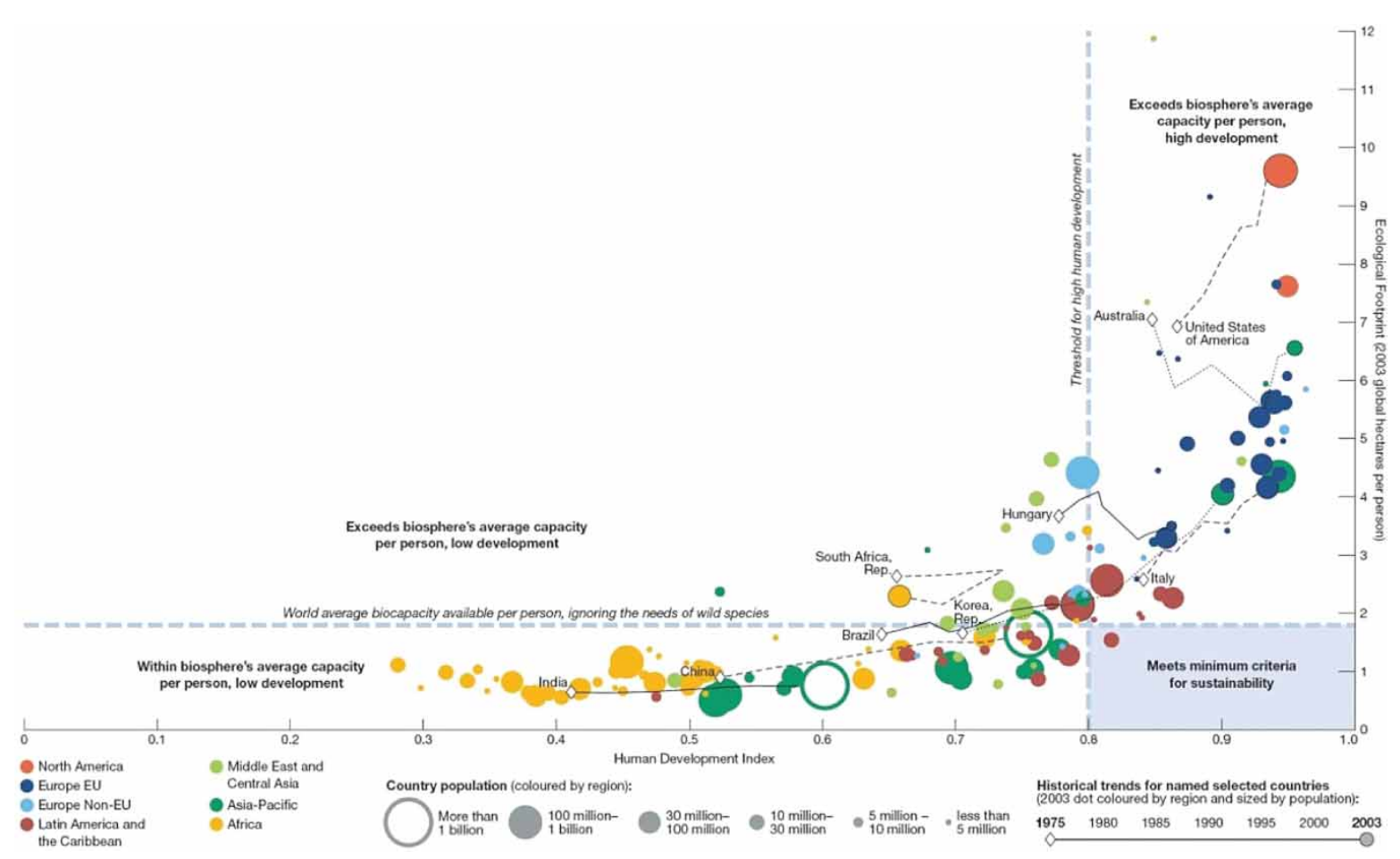

Figure 1. National development trajectories

\section{Minimum standards and built environment characteristics}

EF and HDI criteria can be translated into minimum built environment standards and characteristics, illustrated in Tables 1-3.

\section{The Built Environment Sustainability Tool}

In order to apply the built environment characteristics listed in the Tables 1 and 2 these can be developed into built environment sustainability criteria and contained within a tool called the Built Environment Sustainability Tool, indicated in Table 3.

\section{The study area}

These criteria have been used to evaluate an area of Atteridgeville, a suburb of Pretoria in South Africa (latitude -25.7733, longitude 28.0713). The study area consists of self-built informal housing constructed in a loosely planned grid. Only basic infrastructure in the form of water (brought in by tankers) and some graded roads

Table 1. Ecological Footprint, minimum standards and built environment characteristics.

\begin{tabular}{|c|c|c|}
\hline Ecological Footprint criteria & Minimum standards & Built environment characteristics \\
\hline $\begin{array}{l}\text { Food: Measured by type and amount of } \\
\text { food consumed }\end{array}$ & $\begin{array}{l}\text { Occupants can meet their nutritional requirements } \\
\text { through affordable, low ecological footprint means. }\end{array}$ & $\begin{array}{l}\text { Local markets with low ecological } \\
\text { footprint foods. } \\
\text { Ability to produce low ecological } \\
\text { footprint food. }\end{array}$ \\
\hline $\begin{array}{l}\text { Shelter: Measured by size, utilization } \\
\text { and energy consumption }\end{array}$ & $\begin{array}{l}\text { Occupants can meet shelter requirements through } \\
\text { affordable, low ecological footprint means. }\end{array}$ & $\begin{array}{l}\text { Appropriately sized, resource } \\
\text { efficient accommodation. }\end{array}$ \\
\hline $\begin{array}{l}\text { Mobility: Measured by type of } \\
\text { transport used and distances travelled }\end{array}$ & $\begin{array}{l}\text { Occupants can access daily requirements using low } \\
\text { ecological footprint means. }\end{array}$ & $\begin{array}{l}\text { Daily requirements accessible within } \\
\text { walking distance. } \\
\text { Access to local public transport. }\end{array}$ \\
\hline $\begin{array}{l}\text { Goods: Measured by type and quantity } \\
\text { consumed }\end{array}$ & $\begin{array}{l}\text { Occupants can access required goods through } \\
\text { affordable, low ecological footprint means. }\end{array}$ & $\begin{array}{l}\text { Appropriate goods available locally. } \\
\text { Facilities to support efficient usage } \\
\text { / shared use of goods. }\end{array}$ \\
\hline $\begin{array}{l}\text { Services: Measured by type and } \\
\text { quantity consumed }\end{array}$ & $\begin{array}{l}\text { Occupants can access required services through } \\
\text { affordable, low ecological footprint means. }\end{array}$ & $\begin{array}{l}\text { Appropriate services available } \\
\text { locally. } \\
\text { Facilities to support efficient usage } \\
\text { of services. }\end{array}$ \\
\hline
\end{tabular}


Table 2. Human Development Index, minimum standards and built environment characteristics.

\begin{tabular}{|c|c|c|}
\hline Human Development Index criteria & Minimum standards & Built environment characteristics \\
\hline $\begin{array}{l}\text { Health: A long healthy life, measured by life expectancy at } \\
\text { birth }\end{array}$ & $\begin{array}{l}\text { Occupants can access facilities } \\
\text { required for health. }\end{array}$ & $\begin{array}{l}\text { Access to sports, health, leisure } \\
\text { facilities. } \\
\text { Access to healthy food and clean } \\
\text { water. } \\
\text { No local hazards such as violent } \\
\text { crime and pollution. }\end{array}$ \\
\hline $\begin{array}{l}\text { Knowledge: Measured by the adult literacy rate and } \\
\text { combined primary, secondary, and tertiary gross } \\
\text { enrolment ratio }\end{array}$ & $\begin{array}{l}\text { Occupants can access facilities } \\
\text { required for learning and } \\
\text { education. }\end{array}$ & $\begin{array}{l}\text { Access to primary, secondary, } \\
\text { tertiary and ongoing learning } \\
\text { facilities. }\end{array}$ \\
\hline $\begin{array}{l}\text { Standard of Living: A decent standard of living, as } \\
\text { measure by the GDP per capital in purchasing power } \\
\text { parity (PPP) in terms of US dollars }\end{array}$ & $\begin{array}{l}\text { Occupants can access opportunities } \\
\text { to enable a decent standard of } \\
\text { living. }\end{array}$ & $\begin{array}{l}\text { Access to employment } \\
\text { opportunities. } \\
\text { Self employment opportunities. } \\
\text { Access to support for small } \\
\text { enterprise development. }\end{array}$ \\
\hline
\end{tabular}

exist. Other infrastructure, such as street lighting, storm water drainage, piped water, electricity, parks, schools, health facilities, sports, leisure and retail facilities, is limited or may not exist locally. The study area is typical of many rapidly developing informal settlements that exist around urban areas in Africa.
The built environment sustainability criteria were applied to a household (red rectangle) in the centre of the study area. This household was selected as being representative of the settlement as a whole, and the settlement was selected as it was reasonable typical of more established informal settlements found on the periphery of urban

Table 3. Built Environment Sustainability Tool (BEST).

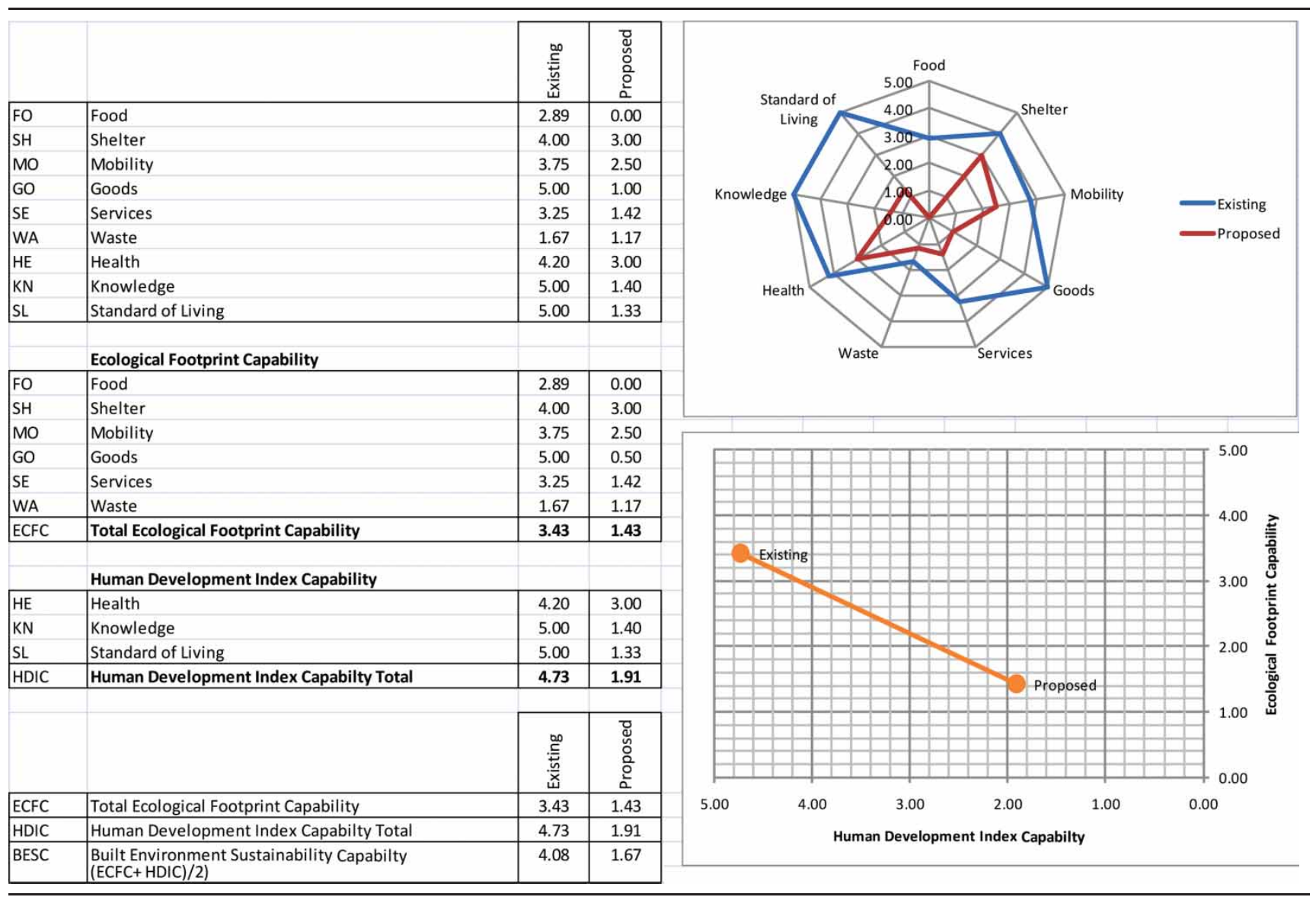




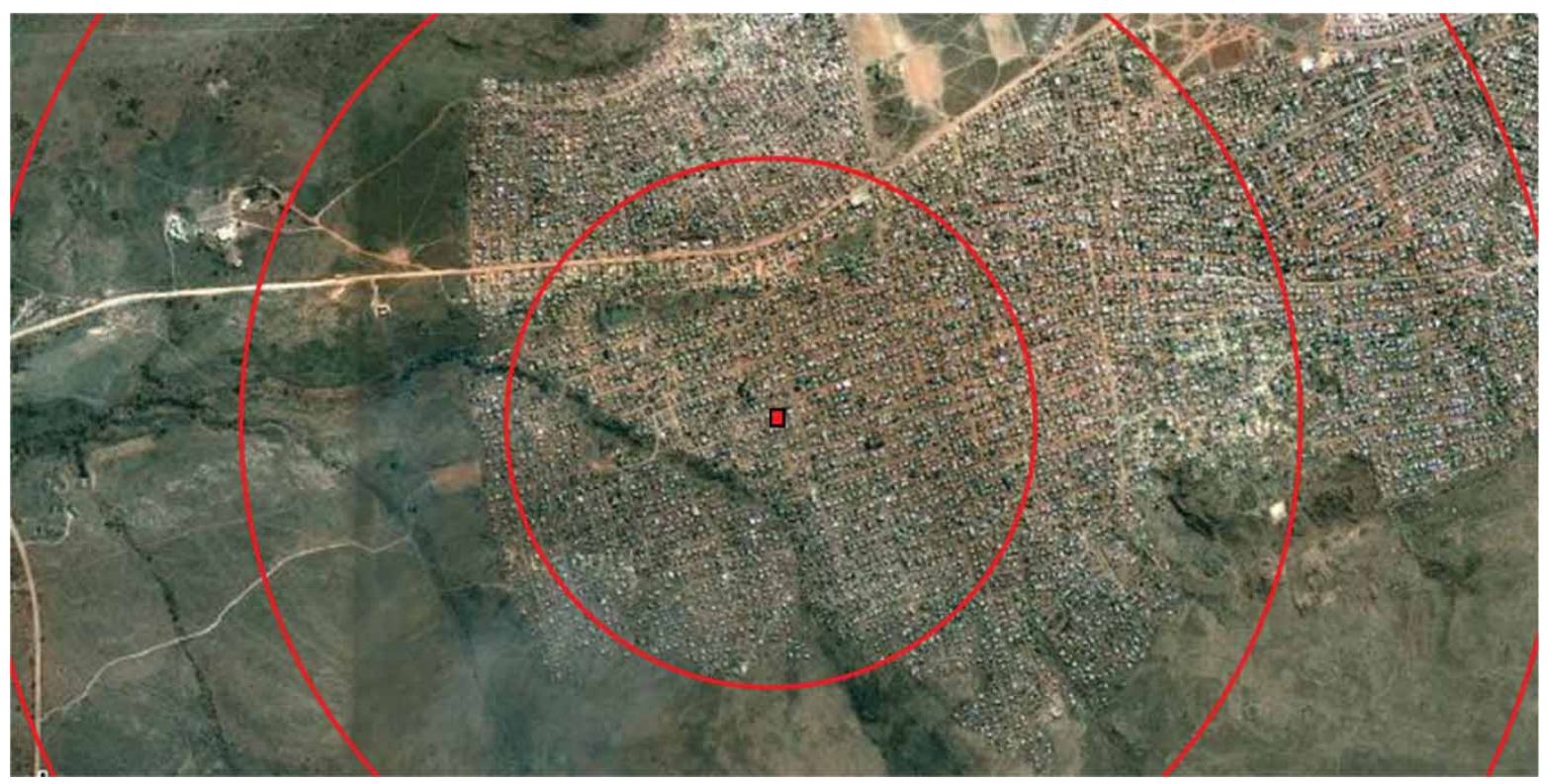

Figure 2. Study area. Red rings indicate 1, 2 and $3 \mathrm{~km}$ distance from household location (red dot)

areas in South Africa. Rings of $1 \mathrm{~km}, 2 \mathrm{~km}$ and $3 \mathrm{~km}$ were then marked on the study area plan, indicated in Figure 2. A survey of the household and area using the criteria was then carried out. A $3 \mathrm{~km}$ radius was used for the evaluation, as this is the distance that is regarded as a reasonable walking distance. This means that households within this area would consider facilities, such as schools, clinics, shops, parks, libraries within this distance, as being 'walkable'. This distance may vary between settlements and in European countries and the USA it is likely that the distance would be considerably lower.

The results of this assessment using the Built Environment Sustainability Tool (BEST) are captured under the 'Existing' column in Table 3 below, in accordance with the following key. ' 0 ' indicates the existence of the specified built environment sustainability criterion on site or within a $3 \mathrm{~km}$ radius of the site, ' 5 ' indicates that this does not exist and ' 3 ' that the criterion is partially fulfilled. For each set of built environment sustainability criteria, such as 'Health', an average value is provided in red; in this case it is 4.20 . This average score provides an indication of the built environment capability within the respective areas, with a low score (near 0) indicating strong capability and a high score (near 5) weak capability.

The BEST results show that the site's built environment capability to support EF and HDI targets is particularly weak in the areas of 'Goods', 'Knowledge' and 'Standard of Living', which all have an average of ' 5 '. The best performing area was 'Waste' with a value of 1.67. These results are also shown in a spider diagram in Figure 2 (the blue line). These results can be used to diagnose gaps and prioritize interventions. In this case, built environment capability gaps exist in 'Knowledge', 'Standard of
Living' and 'Goods' and interventions to address these should be prioritized.

Overall, BEST measures of the HDI and EF capability can also be derived. Figure 3 indicates that the site has an EF capability of 3.43 and an HDI Capability of 4.73 . The BEST also shows that the combined built environment capability is 4.08 . This suggests that the site has a very low capability to support the achievement of HDI sustainability targets. It also shows that while the site has a better capability to support the achievement of EF targets, this is still very poor. These BEST capability measurements reflect South Africa's location, shown in Figure 2.

\section{Sustainable African Built Environments}

Given the baseline results, what would be suitable interventions to support sustainability in this area? What would 'sustainable African built environments' in this location look like?

In order to begin to develop and evaluate ideas, a number of options were introduced into the tool and the impact assessed. These interventions are:

- Urban Gardens: Provides access to local food gardens.

- Tool Hire: Provides access to local tool and equipment hire or sharing.

- Urban Market: Provides access to local markets for food and goods.

- Solar Water Heating: Provides solar water heating to houses.

- Local Multipurpose School: Provides access to a preschool, primary and secondary school and a learning 
resource centre with information and communications technology and support for ongoing learning.

- Rainwater Harvesting: Provides rainwater harvesting systems to houses.

The overall impact of the interventions in terms of improved built environment capability was ascertained from BEST total scores. This indicates that 'Urban Gardens', 'Urban Markets', and 'Multipurpose School' have the highest BEST scores at 32, 32 and 40, respectively, and that 'Tool Hire', 'Solar Water Heating' and 'Rainwater Harvesting' have the lowest, at 9, 8 and 10, respectively.

The BEST results are surprising as they indicate that conventional greening interventions such as the installation of solar water heaters, water efficiency programmes and energy efficient housing may have a lower impact on local sustainability than urban agriculture, multipurpose learning centres and local markets.

\section{Conclusion}

The paper concludes that the investigation into the implications of the HDI-EF definition of sustainability for the built environments in African developing country contexts is a valuable exercise and leads to surprising results.

Translating the HDI-EF definition into a tool (the Built Environment Sustainability Tool) provides an innovative and original way of assessing the sustainability of urban environments. This tool can not only be used to assess the sustainability of urban environments but also the impact of potential interventions. This makes it potentially a highly valuable planning and decision support tool. It should however be noted that further refinement and testing of the tool will be needed to confirm that the tool can be applied in an unbiased way across a diverse range of environments.

The findings of using the tool are surprising in that they suggest that conventional greening interventions such as the solar water heater and water efficiency programmes may be less effective and efficient in improving the sustainability of developing African informal settlements than the development of urban agriculture, local markets and local multipurpose community learning resource centres. While this is unexpected, further consideration of the local context and sustainability suggests that this finding may be correct and therefore the tool may be valuable in identifying and prioritizing the most appropriate and pressing interventions required to support sustainability within this context.

Further research on the tool and potential sustainability interventions should be carried out in order to understand how more responsive and appropriate sustainable African built environments can be developed.

\section{References}

Barker, T. (2007). Climate change 2007: an assessment of the intergovernmental panel on climate change, in Change, November: $12-17$.

Curwell, S. \& Cooper, I. (1998). The implications of urban sustainability, in Building Research \& Information, 26(12), $17-28$.

Holden, E. \& Linnerud, K. (2007). The sustainable development area: satisfying basic needs and safeguarding ecological sustainability, in Sustainable Development, 15, 174-187.

Moran, D.D. et al. (2008). Measuring sustainable developmentnation by nation, in Ecological Economics, 64(3), 470-474.

United Nations Development Programme (2007). Human Development Report 2007/2008, New York.

United Nations Environment Programme (2010). The Emissions Gap Report, November.

Wackernagel, M. \& Yount, D. (2000). Footprints for sustainability: the next steps, in Environment, Development and Sustainability 2, Berlin: Kluwer Academic, pp. 21-42.

Winkler, H. (ed.) (2007). Long Term Mitigation Scenarios: Technical Report. Prepared by the Energy Research Centre for Department of Environment Affairs and Tourism, Pretoria, October.

World Wildlife Fund (2006). The Living Planet Report. Available at: www.panda.org/news_facts/publications/living_planet_ report/linving_planet_report_timeline/index.cfm 